\title{
Case study of STEM education in the family
}

\author{
Yan Mei \\ Rizhao Polytechnic, Rizhao City, Shandong 276826, China \\ yanmei@126.com
}

Keywords: STEM family education; scientific literacy; case study

\begin{abstract}
To vigorously promote the STEM education in the background of international science education, the STEM education in the family education to promote the application process of several representative cases, using the basic theory and methods of science education, learning content and learning process of STEM from STEM resources, the role of parents and family to explore should note that the STEM education in family problems, thinking about people STEM education in the family.
\end{abstract}

\section{Introduction}

STEM education consists of subjects: Science (Science), Technology (Technology), Engineering (Engineering), and Mathematics (Mathematics). This is the United States government in order to develop in the world's leading talent competition in the future, a programme of education and development, including postdoctoral education from pre-school to grade level of all educational activities, including formal education (classroom education) and informal education (extracurricular projects).

The STEM of science education in the family and it is rare, but in view of the current school classes, classes, experimental equipment limitations, many schools of science education in primary school is relatively weak, so there is a part of conscientious parents try and their children with inquiry based science learning activities. In fact, the implementation of the depth of STEM in the family oriented science curriculum will be faced with many obstacles, one is the parents do not know how to lead the children to carry on the scientific inquiry, lack of self-confidence, that is the task of the school science education. Two, there is not much resources to support the design of inquiry STEM science education, and three, many children spend a lot of time playing computer games and mobile phones, and may have no patience with depth studies. Then, through a few typical cases to analyze family education in the STEM education should pay attention to the problem.

\section{Case 1 and Analysis}

\subsection{Case 1}

The market is flooded with a large number of educational toys, some STEM science toy became the new darling of the children, childhood love all kinds of toy building block Yong Ho, the mother carefully selected the new STEM science toys, Yong Hao every day want to build a edifice, gear and splicing small world, anti-theft alarm, overpass and maze, Yong Hao can love more simple programming STEM toys, my mother bought a suite of LEGO education, to give him a robot teaching extracurricular classes, he registered online forum Lego, from now on, Yong Hao the most happy thing is to build a good works, and debugging success let the robot move.

\subsection{Case analysis}

In recent years, the STEM education has been in full swing into preschool and kindergarten education program, comply with the STEM children's education boom, with STEM education toys 
also came into being, STEM toys, is to put those esoteric knowledge into science and engineering technology have fun and not boring game, fully tap the children's curiosity and encourage them to explore the world of the rules, understand how technology is changing the world and our life. In the future, it will become the basic way of thinking in daily life to train children's interdisciplinary thinking mode through STEM education. Children will make use of the Internet to study subject knowledge, and the use of various digital tools to explore interdisciplinary issues will become the norm. [1]., STEM education for children is also possible in the family.

\subsection{What are the resources for STEM education in the family? What are the characteristics of these resources?}

Popular STEM toys such as building toys (magnetic construction toys, toys, building space concept building electrical toys), toys, toys, all kinds of gear circuit building blocks to build creative toys, board games, Lego series toys, electric toys, robot Science Kit (natural science experiment, energy technology experiment, dynamic experiment for mechanical Engineering) etc..

The common characteristic of these resources is to stimulate children's interest and curiosity and imagination, to meet the needs of children of parents, the use of STEM toys can encourage them to raise new questions, new tasks, encourage them to a problem about the different solutions, challenge their children have the idea, and then create a chance to verify them. At the same time may also lead to new research activities. High quality resources (people, environment, equipment, information, ideas, sources, networks, etc.) must be able to support children constantly to explore possibilities. From the case we can see that in order to support the son of continuous learning, Yong Hao's mother can not only provide his popular STAEM toys, more important is to continue to provide better resources for the son, such as BBS, robot classes. These resources can continue to support children's new research and innovation activities.

\section{Case 2 and Analysis}

\subsection{Case 2}

Ning's mother is a university teacher, with the network open class, mu, micro classes, forums and other resources to learn relevant content of STEM education, so she recruited 3 neighbor and son almost a child at home, started a family of STEM education, according to the online resources, only some the life of common materials such as paper, ice cream sticks, all kinds of beans, plastic bottles, Straw and paper clips, tea boxes, fruit and so on, to accompany the children to carry out a series of courses, such as the small bridge designer (built bridge with the ice cream bar), designer (making the tea box with a plastic bottle, a small boat) the artist (with soybeans, peas, mung bean, black rice, rice and other art paintings), architects (with Straw, small clip built cube). And according to Chinese science and technology education in the journal plans carried out "my instruments" "do" Pinball "my LED" lamp "my toothbrush" scientific inquiry activities, several children together, learning together, not only improves the ability of design and production, but also improve the ability of communication, cooperation and sharing.

\subsection{Case analysis}

Through this example, we can see that sometimes STEM education does not necessarily need to support AIDS on the tall, but this case has its particularity lies in: Ning Ning mother is a love of learning, to keep up with the development of the times, make full use of cyber source to learn to use, there are a lot of resources on the Internet, but also STEM the Mu class, parents can make full use of these resources, learning teaching, and grow with the child is not an empty talk, many parents to educate children constantly learning.

\subsection{What are the roles and roles of parents in STEM education in the family?}

Parents should first be an inquiry, only parents understand the concept of STEM, master the 
methods and scientific knowledge and skills, scientific inquiry activities together to better and children, can let the children better understand the research methods, skills and process of inquiry; parents should also be the creation of a good the environment, create suitable environment of scientific inquiry is the necessary condition to explore the characteristics and changes of parents to guide children to explore things around, to create a relaxed, lively, free and divergent research atmosphere, provide all kinds of convenience for children to explore the physical and psychological support for their parents; should be a guide and organizer. Research on children's ability to learn is that children are active learners, children can be effective under the guidance of learning basic knowledge and skills of.[2] more so the role of parents is "guide", rather than "teaching". Parents help children to think and discuss the problem by creating scenarios and guiding them to think and discuss the problem step by step. The role of the parents is also reflected in: to make full use of children's existing experience, the use of inquiry activities to focus their attention, cultivate children's ability to cooperate, through the creative problems of promoting children's inquiry, and help them make records, urging them to work to help them understand the scientific concept of solid core.

\section{Case 3 and Analysis}

\subsection{Case 3}

My mother began to accompany the tsunami science experiment, a variety of fun, Dad had led him to do fun and small production, the tsunami to things around is full of curiosity, and dad make a bird feeder, personalized pen, can have a toy car, the whole function of the bird's nest, paper bridge mine detector, rocket parachute, solar emergency water purifier etc.. Mom and the design of multi functional fabric bags, clothing, paper, bicycle model, ideal home, plant insect survey paper etc.. Mom and dad to contact the life practice, to solve practical problems encountered in life, with a tsunami like scientists working process, through a series of problems, such as setting the situation put forward the scientific and engineering problems, the design and implementation of a clear investigation, seek solutions, try adjustment plan, diy. The 10 year old tsunami has become a small repair worker in the family, and mother says the tsunami is a veritable little engineer.

\subsection{Case analysis}

There are a lot of STEM education in family education, the key is whether parents have STEM consciousness and methods of education. In the case of a tsunami like mom and dad have consciousness and good practice, with his son from the reality of life, design can make life more interesting and better small inventions, small production. In fact, even the most simple scientific phenomena and problems, it can be found in the shadow of the human life, find it into the way of technology and engineering; when the content of life and learning mutually, learning is more effective, when they solve real life problems, think of not only technology, is design, engineering, also must consider the scientific principle and rules involved, only follow the principle and law, nature can truly find the problem.

\subsection{Then what are the contents and the general learning process of STEM science education in the family?}

First of all, we should guide children to understand the relationship between nature, environment and human life. Nature is the best place for science education and the best teacher. The leaves change color, fore shoots, flying butterflies can become the object of research on children. Children need to develop an ecological awareness of the environment, and understand how human activities and environments change, what causes this change, and what kind of response citizens should make. So parents can find practical STEM theme activities from their lives. Plants such as homemade hand sanitizer, homemade enzyme, composting, making rubbings, amber painting, leaf area measurement and so on 15. What are the roles of science and technology in guiding children to think about the problems faced by society? Inspire children to protect the environment, from my enthusiasm and 
awareness.

Secondly, we should guide children to explore the characteristics and changes of things around them. Let the children observe and explore common weather phenomena, to observe the change of wind, clouds, seasons, ice, snow, rain, explore the thunder weather phenomenon. And through the game, experiments exploring various forces (gravity, buoyancy, friction), light, heat, sound, magnetic and electrical phenomena; such as DIY fiber, rainbow, send and receiver using balloons sound, fruit batteries and so on children will become a good STEM theme of scientific inquiry activities.

Finally, parents should accompany children with "doing science", in July 2011 the United States announced the "K12 grade science education framework: practice, concept, and the core concept of" cross file is the foundation of a new generation of science education standards development, "the framework should encourage students to learn scientific concepts through practical science. [3] in the course of "science", parents should pay attention to some key points of STEM theme in scientific inquiry and the inquiry process, parents should understand the value of education is: STEM application of knowledge and skills to understand and are equally important, teaching for understanding." "Teaching for understanding" is an educational model proposed by the Graduate School of education at Harvard University: "understanding means the ability to apply the learning knowledge flexibly.". [4] learning is the result of the combination of knowledge and Practice (learning, thinking, doing), can not be separated from learning and practice, into two different content and process.

Parents lead children to STEM education scientific inquiry activities specific usually include the following basic links: 1 . research topic, put forward to determine the children's concerns, to choose suitable age and experience level of children, can cause problems of their interest in exploring. 2. speculation and discussion ---- parents should encourage children to speculate, guess and design the problem solving methods. 3, design and test, let the children get the facts on the basis of observation and empirical materials, guide the children to use multiple senses to experience the world, this stage put forward specific scientific questions, clear the problem to solve the problem, design solutions. 4., processing information and data - to allow children to describe things objectively, parents should guide children in an appropriate way to record activities of information, analysis and interpretation of data, the use of mathematical and computational thinking. 5. expressing and communicating --- let children express themselves and listen to others, parents listen, encourage and repeat key statements of children, find and guide children to pay attention to the contradictions and inconsistencies of their findings. 6., improve the solution and application ---- collect opinions, complete the design plan, and apply to the actual life. Scientific inquiry activities can be the whole process of the nested loop, can also be part of the problem, and according to the situation and decide, parents should choose relevant links according to the learning activities of the content, do not need to complete each activity throughout the whole process of scientific inquiry.

\section{Conclusion}

We know that the new American science education standard NGSS emphasizes that scientific concepts should be constructed continuously from kindergarten to 12 years. [5] University of Cincinnati Professor Mo and more in-depth study on how to implement the STEM education in the kindergarten, she published "STEM teaching in early childhood education in 2013" (Teaching STEM In The Early Years) a book summarizes the current United States in early science and mathematics education four key educational practice, and take them as the theoretical guidance for STEM education in preschool education stage. These four educational practices are purposeful education, teaching for understanding, encouraging inquiry and providing real life. The core of [6]STEM education is the integration of science, technology, engineering and mathematics integration, it is interdisciplinary learning, it is learning a project based on the learning process, this is the purpose of the process of inquiry, and encourage a positive, cooperative learning, and ultimately the best able to solve practical problems life, so that it can get good results.

Today, with the rapid development of science and technology, the quality of science is one of the 
most important manifestations of a person's overall quality. In modern society, a person needs to have the basic scientific quality, especially in the current situation of social competition is more and more intense, more need to have the spirit of innovation and innovation ability. Science education needs parents' participation, parents should establish the correct concept of scientific education, create a good psychological environment construction, support and guide the children experience, improve their scientific ability, and good at random education, because the cultivation of scientific ideas and concepts to the parents in their daily life, to answer the problem of child good at giving systematic guidance at the same time, to satisfy their curiosity, enough patience to accompany them to explore the mysteries of life in the world, and ultimately develop the habit of scientific inquiry. Cultivate children's scientific literacy is not a short duration of time things, and the parents of their children is profound and lasting, so parents should assume their responsibilities, take advantage of family education, scientific enlightenment education for children, let the children of Nong Houxing scientific interest. To guide children into the wonderful world of science, to discover the joys of scientific exploration, to rebuild the spiritual world of children, and to help children return to the spiritual home to protect their true life.

\section{Acknowledgements}

Fund Project: Shandong Provincial College of Humanities and social science program 2017. Name: Research on professional ability training of Preschool Education Majors From the perspective of STEM Education. Item number: J17RA157.

\section{References}

[1] Cen sang. Family education. [M]. Beijing: People's education press, 1997.

[2] Zhang Chunxing. Educational psychology. [M]. Hangzhou: Zhejiang Education Press, 1998.

[3] Zhao Zhongxin. Education of children in Chinese families. [M]. Beijing: China Legal Publishing House, 2000.

[4] Livy. School education psychology for primary school students [M]. Guangzhou: Guangdong higher education press, 2001.

[5] Chen Qi, et al. Contemporary psychology of education [M]. Beijing: Beijing Normal University press, 1997. 